\title{
Household Preferences to Reduce Their Greenhouse Gas Footprint: A Comparative Study from Four European Cities
}

\author{
Bore Sköld 1,* , Marta Baltruszewicz 2® ${ }^{1}$, Carlo Aall ${ }^{2}$, Camilla Andersson ${ }^{1,3}$, Alina Herrmann ${ }^{4}$, \\ Dorothee Amelung ${ }^{5}$, Carine Barbier ${ }^{6}$, Maria Nilsson ${ }^{1}\left(\mathbb{D}\right.$, Sébastien Bruyère ${ }^{7}$ \\ and Rainer Sauerborn 8,9 \\ 1 Department of Public Health and Clinical Medicine, Epidemiology and Global Health, Umeå University, \\ 90187 Umeå, Sweden; camilla.andersson@umu.se (C.A.); maria.nilsson@umu.se (M.N.) \\ 2 Western Norway Research Institute, 6856 Sogndal, Norway; marta.baltruszewicz@gmail.com (M.B.); \\ caa@vestforsk.no (C.A.) \\ 3 Department of Radiation Sciences, Umeå University, 90187 Umeå, Sweden \\ 4 Heidelberg Institute of Global Health, Heidelberg University Hospital, 69120 Heidelberg, Germany; \\ alina.herrmann@uni-heidelberg.de \\ 5 School of Health Sciences, University of Surrey, Surrey GU27XH, UK; \\ dorothee.amelung@psychologie.uni-heidelberg.de \\ 6 Centre International de Recherche sur l'Environnement et le Développement, 94736 Paris, France; \\ barbier@centre-cired.fr \\ 7 TEC Conseil, 13001 Marseille, France; sebastien.bruyere@tec-conseil.com \\ 8 Institute of Public Health, Heidelberg University, 69120 Heidelberg, Germany; \\ rainer.sauerborn@urz.uni-heidelberg.de \\ 9 Harvard Chan School of Public Health, Boston, MA 02115, USA \\ * Correspondence: bore.skold@umu.se; Tel.: +46-70-654-8683
}

Received: 7 October 2018; Accepted: 24 October 2018; Published: 5 November 2018

check for updates

\begin{abstract}
This paper investigates households' preferences to reduce their carbon footprint (CF) measured in carbon dioxide equivalents $\left(\mathrm{CO}_{2} \mathrm{e}\right)$. It assumes that a substantial $\mathrm{CF}$ reduction of households is essential to reach the $1.5^{\circ} \mathrm{C}$ goal under the Paris Agreement. Data was collected in four mid-size cities in France, Germany, Norway, and Sweden. Quantitative data was obtained from 308 households using a CF calculator based on a questionnaire, and a simulation game. The latter investigated households' preferences when being confronted with the objective to reduce their CF by 50 percent by 2030 in a voluntary and forced scenario. Our results show that the greater the $\mathrm{CO}_{2}$ e-reduction potential of a mitigation action, the less willing a household was to implement that action. Households preferred actions with moderate lifestyle changes foremost in the food sector. Voluntarily, households reached a $25 \%$ footprint reduction by 2030 . To reach a substantial reduction of 50 percent, households needed to choose actions that meant considerable lifestyle changes, mainly related to mobility. Given our results, the $1.5^{\circ} \mathrm{C}$ goal is unlikely to be realizable currently, unless households receive major policy support. Lastly, the strikingly similar preferences of households in the four European cities investigated seem to justify strong EU and international policies.
\end{abstract}

Keywords: Greenhouse gases; $\mathrm{CO}_{2}$; emission; households; preferences; climate change; mitigation; Paris agreement; Europe; carbon footprint

\section{Introduction}

The international climate goals set out in the Paris Agreement 2015 will require 'net zero' anthropogenic greenhouse gas (GHG) emissions by 2100 according to the consensus reports by the 
Intergovernmental Panel on Climate Change (IPCC) [1]. If this goal is not achieved, climate change is expected to cause devastating negative effects on nature and society. Generally, achieving international climate change mitigation goals in high-income (HICs) will require drastic improvements in energy efficiency as well as profound lifestyle changes [2-12]. While direct emissions from production of energy, other products and services are an integral part of the IPCC mitigation discourse, less emphasis has been given to indirect emissions by advocating lifestyle and end-use consumption changes [13-16]. GHG emissions can be calculated by taking consumption-or a production-based approach. The latter refers to the territorial emissions of a given region, whereas the first approach, consumption-based, takes into account emissions embedded in, for example, trade by looking into the demand side of production. When calculating GHG emissions from the consumption side, including both direct and indirect emissions, households contribute up to $72 \%$ of GHG emissions globally $[17,18]$. Whereas the direct production-related GHG emissions in many HICs for the last decades decreased by $3 \%$ between 1990-2008, consumption-related GHG emissions, in particular emissions from private consumption, increased by $11 \%$ [19]. Studies addressing household level GHG mitigation have often been framed in contexts of voluntary and autonomous mitigation actions [20] - to a lesser extent looking at mandatory mitigation policies or regulations and what effect that would have on people [21]. Furthermore, greater focus has been on the analysis of the effects of households' consumption patterns, as opposed to that of consumption volumes [4,18], in particular with respect to GHG emissions per unit of consumption [22] and efficiency actions such as, for example, changing to an electric car, installing a heat pump, etc. [23,24]. Moreover, studies have indicated that it is difficult to engage households in mitigation actions that will result in changes in lifestyles with substantial GHG reduction. Furthermore, research is limited on the connection between household's consumption, GHG emissions, and behavior change $[25,26]$.

Upon the adoption of the Paris Agreement in 2015, the Conference of Parties (COP) to the United Nations Framework Convention on Climate Change (UNFCCC) invited the IPCC to provide a special report in 2018 on the impacts of global warming of $1.5^{\circ} \mathrm{C}$ above pre-industrial levels and related global GHG emission pathways. This paper will contribute to this effort by investigating household strategies aimed at decarbonizing their emissions to achieve the $1.5^{\circ} \mathrm{C}$ goal. This study is produced within the framework of the project "Household Preferences for Reducing Greenhouse Gas Emissions in Four European High Income Countries" (HOPE), and addresses the following research questions:

(1) What are the main determinants of households' carbon footprints in four high income mid-size European cities?

(2) Which mitigation actions do households prefer to implement voluntarily to reduce their carbon footprint?

(3) Which mitigation actions do households need to implement to reduce their carbon footprint by 50 percent?

(4) What patterns can be found in $\mathrm{CO}_{2} \mathrm{e}$ reductions and reduction potential between high and low emitting households?

\section{Materials and Methods}

The HOPE project took a mixed-methods approach in order to assess households' preferences to reduce greenhouse gas emissions. The mixed-methods design comprised three steps labeled Interactions. The first two Interactions were purely quantitative and the third interaction was purely qualitative. Only quantitative results are presented in this paper including a short brief of the sampling and recruitment procedures in order to focus more on the data collection and analysis of Interactions 1 and 2. A more detailed description of the entire study protocol is given elsewhere [27].

Data was collected between June and November 2016 in households in four medium sized cities situated in four European high-income countries (HICs): Bergen in Norway, Communauté du Pays d'Aix in France, Mannheim in Germany, and Umeå in Sweden. We chose one city per country as a case study in order to engage stakeholders on a city level into the process of research 
and dissemination. Henceforth, the investigated cities will be referred to by country names. Initially, a thorough protocol and guidelines were developed to secure comparable procedures in every country after which invitation letters were sent by mail in those countries where city registries were available. The letters were standardized across countries and translated to local languages. They included general information, an announcement of incentives, a detailed information sheet and an informed consent form to be filled in. Given the thorough protocol and a limited budget, two incentives were offered to increase participation rate: $€ 25$ vouchers upon completion of interaction 2 and a lottery ticket to win a prize worth around $€ 1000$ upon completion of interaction 3 . The combined incentives meant to encourage both "risk averse" and "risk seeking" people, further explained by Herrmann et al. [25].

Interaction 1 was assessed by a self-report questionnaire that took approximately two hours for each household to fill in (for full questionnaire in English see the HOPE questionnaire (Supplementary Materials: HOPE_questionnaire.pdf). The assessment included detailed questions concerning the households' demographics, consumption, and expenditures in the areas of housing, mobility, food, and other consumption. For instance, households were asked to report their annual car mileage and expenditures for their car. In the food section, household representatives were asked to fill in their weekly use of a certain food item in $\mathrm{kg}$. As not all types of foods were prompted, we introduced a fixed value for Other food, which was added to the $\mathrm{CO}_{2} \mathrm{e}$ footprint of the prompted food items. This value was calculated from average values of the consumption of food not included in the questionnaire (in particular: eggs and eggs products, cereals, nuts, potatoes, rice, vegetable fats, sweets and sugar, mineral water, tee and infusions, coffee, and alcoholic drinks) and resulted in $611.68 \mathrm{~kg} \mathrm{CO}_{2}$ e per person per year. Furthermore, socioeconomic characteristics of households were collected. The information provided by the questionnaire yielded a baseline carbon footprint (CF) for each household. This was calculated and presented using a Footprint Calculation and Simulation-Tool (FCS-Tool), especially developed for this study. The development and exact functioning of the FCS-Tool is described elsewhere [28]. A chart presenting the structure of households' baseline CF is shown in the Supplementary Materials (Supplementary Materials: Footprint.pdf).

The households were informed about the EU's mitigation goals to stay below the $1.5^{\circ} \mathrm{C}$ warming ceiling and that it would require a $50 \%$ reduction of GHG emissions by 2030 across all sectors of society, including private households $[29,30]$. The interaction was conducted by one participant, who represented the whole household, in order to rule out bias from group dynamics. The FCS-tool generated 65 individualized action cards presenting mitigation actions in consumption patterns and levels (e.g., "Reduce your car use by 30\%"). Each card displayed for each household: (1) How much $\mathrm{CO}_{2} \mathrm{e}$ could be saved by implementing this action per year; (2) how much this action would cost/save the household in monetary terms; and (3) what health effects ("co-benefits"), if any, the respective action would generate. The calculations and methods behind the action card's reduction potential, cost-effect and health co-benefits were decided and evaluated in a pilot study performed in 2015 by the HOPE-team. Information about calculations and methods, can be found on the web (http:/ /hopeproject.net/?page_id=1052\&lang=en) and is described by Herrman et al. in a study protocol [27].

The procedure in Interaction 2 took place as follows: First, we asked the participant to read and rate all action cards. Second, we confronted the participant with two sequential scenarios, 'voluntary' and 'forced' (abridged as Sim in notations) in order to simulate household's CF reduction, using the following words:

1. Sim1 (voluntary): “Which action would you actually like to implement to reduce your carbon footprint by $50 \%$ by 2030 ? Choose and rank action cards. Start with the action you would be most willing to implement. You may choose up to 30 actions in total."

The choices were entered in the FCS-Tool, which calculated how much the CF would reduce if these actions were implemented. If the reduction was less than $50 \%$, the participant was confronted with a second task: 
2. Sim2 (forced): "Which actions would you choose if you were forced to reduce your carbon footprint by 2030? Continue your rank order from simulation 1 . You may choose up to 30 actions in total."

During the second scenario, the participant received continuous feedback from the interviewer about the current reduction level. The simulation ended when the $50 \%$ target was reached or when it was not technically feasible to choose any more action cards. Moreover, some action cards were not applicable- thus not available- to households, either if the action was not possible to implement for this household (e.g., solar collectors in a ground floor apartment) or because the action was already done by the household (e.g., eating less meat in a vegetarian household). In cases where participants chose to stick with their Sim1 result throughout Sim2, their response counted only once. Furthermore, some actions were mutually exclusive such as eating $30 \%$ more vegetarian food, eating $60 \%$ more vegetarian food, and becoming a vegetarian.

Altogether, data from 309 households were collected and one observation was removed from the sample due to missing data. The repartition by countries was as follows: Germany $n=106+1$ missing; France $n=70$; Norway $n=58$; and Sweden $n=74$. All calculations and analysis were performed using the software R v.3.2.1 ( $\mathrm{R}$ foundation for Statistical Computing, Vienna, Austria). Emission variables with skewed distributions were log-transformed to more accurately distinguish variation. Summary statistics for continuous variables were presented as medians and 25th-75th percentile range, and for categorical variables as frequencies (\%).

Linear regression models were used to assess associations between (1) reduction potential (independent variable) and chosen actions (dependent variable) and (2) household baseline CF (independent variable) and household income (dependent variable). In order to improve comparisons across households of different sizes, some variables were weighted using "consumption units" (CU). We used the Organisation for Economic Co-operation and Development (OECD)-modified scale [31], with the following weights: 1 for the household head, 0.5 for each additional adult member and 0.3 for each child (under 15). For example, if a household including 2 parents and 2 children under 15, had annual GHG emissions of 15 tons $\mathrm{CO}_{2} \mathrm{e}$, the annual footprint per consumption unit was $15 /(1+0.5+2 \times 0.3)=7.14$ tons per CU per year. The data of the four studied countries were analyzed separately, as well as pooled, however, all results were aggregated to give a descriptive picture of the full data including all countries if not otherwise stated.

\section{Results}

\subsection{Size and Composition of the Households' Baseline Carbon Footprint}

Figure 1 shows the median carbon footprint (CF) of our investigated countries at baseline for each household sector; mobility, food, housing, and other consumption (all CF estimates are available in the supplementary files. Tables S1-S11 are in S1 (Supplementary Materials: Spreadsheet) and boxplots in the Sector PDF (Supplementary Materials: Sector_spec.pdf).

The households' median baseline carbon footprint (CF) was lowest for Swedish participants (7.3 tons), followed by the French (10 tons), German (10.2 tons), and Norwegian participants with 11.3 tons $\mathrm{CO}_{2} \mathrm{e}$ per consumption unit (cu) per year. Mobility stood out as the highest contributing sector to $\mathrm{CO}_{2} \mathrm{e}$ emissions across all countries, accounting for an average of $34 \%$ of the households' baseline $\mathrm{CF}$ with a median value of 2.9 tons $\mathrm{CO}_{2}$ e per $\mathrm{CU}$ per year. The food sector made out $30 \%$ with 2.6 tons $\mathrm{CO}_{2} \mathrm{e}$, followed by the housing sector ( $21 \%$ and 1.8 ton) and other consumption (15\% and 1.3 ton). Altogether the median baseline household $\mathrm{CF}$ was 9.5 tons $\mathrm{CO}_{2} \mathrm{e}$ per $\mathrm{CU}$ per year (see Table S1 (Supplementary Materials: Tables spreadsheet)). To a large extent, the baseline CF for housing was made up by emissions from Heating, which was the highest contributing commodity to this sector in all countries with a total of 0.5 tons / cu covering $44 \%$ of this sectors total baseline CF. Furniture and renovation contributed the least within the housing sector (3\%) along with House construction (1\%) (see Table S2 (Supplementary Materials: Tables spreadsheet)). Moreover, housing was a sector built by 
GHG emissions largely from energy consumption which resulted in some variations between countries depending on what major source of energy they used (nuclear, hydropower, district heating, etc.) and what the consumer price was at the time of the study $(\mathrm{kWh} / €)$. Food did not show much country wise variation with the exception of France due to higher numbers of reported meals eaten at restaurants/school. The highest contributing food commodity was the category Other food (37\%) followed by Restaurants/school (24\%), Dairy (14\%), and Red meat (11\%) (see Table S3 (Supplementary Materials: Tables spreadsheet)). As shown in Figure 1 (see Table S4 (Supplementary Materials: Tables spreadsheet) for detailed information). Other consumption was the least emission-heavy sector with the exception of Sweden, where housing had the lowest median value of the four sectors. Mobility's baseline CF was predominantly composed by the commodities Car, motorcycles and other motorized vehicles (hence referred to as Car) and Plane with 1.4 and 0.9 tons of $\mathrm{CO}_{2} \mathrm{e}$, respectively, together accounting for more than $98 \%$ of this sectors total baseline CF (see Table S5 (Supplementary Materials: Tables spreadsheet)). As a result of the mobility sector's vast contribution to the households' total emissions, the commodities Car and Plane were dissected by country to grasp a wider understanding of the underlying factors affecting their impact on the CF. The annual distances for households' flights per capita were noted in three subcategories: Domestic, inter-European, and intercontinental. The emissions attributed to these flights were directly connected to the distances of the voyages. The difference between the subcategories showed that domestic flights yielded the shortest recorded distance followed by inter-European-, and intercontinental flights for all countries, with the exception of Norway, which had over half of their recorded distances attributed to inter-European flights. For Germany, $84 \%$ was intercontinental flights, and for France almost 70\%. The Swedish record were quite evenly distributed between all three subcategories. The median flight distance varied from around six-to eight thousand km per person and year for Germany, France, and Sweden. Norway had a median distance recorded to nearly 13 thousand $\mathrm{km}$ per person per year, comparable to a round-trip from Berlin to New York (see Table S6 (Supplementary Materials: Tables spreadsheet)). The analysis of distances travelled by cars revealed that French and German participants mainly used their cars for commuting, whereas the Scandinavian countries used theirs for holidays or other local travel to a relatively higher extent. On average, households in France and Germany travelled $36 \mathrm{~km}$, and $27 \mathrm{~km}$ per day, respectively, whilst households in Sweden and Norway both travelled less than $17 \mathrm{~km}$ (14 km and $16 \mathrm{~km}$, respectively) (see Table S7 (Supplementary Materials: Tables spreadsheet)). 


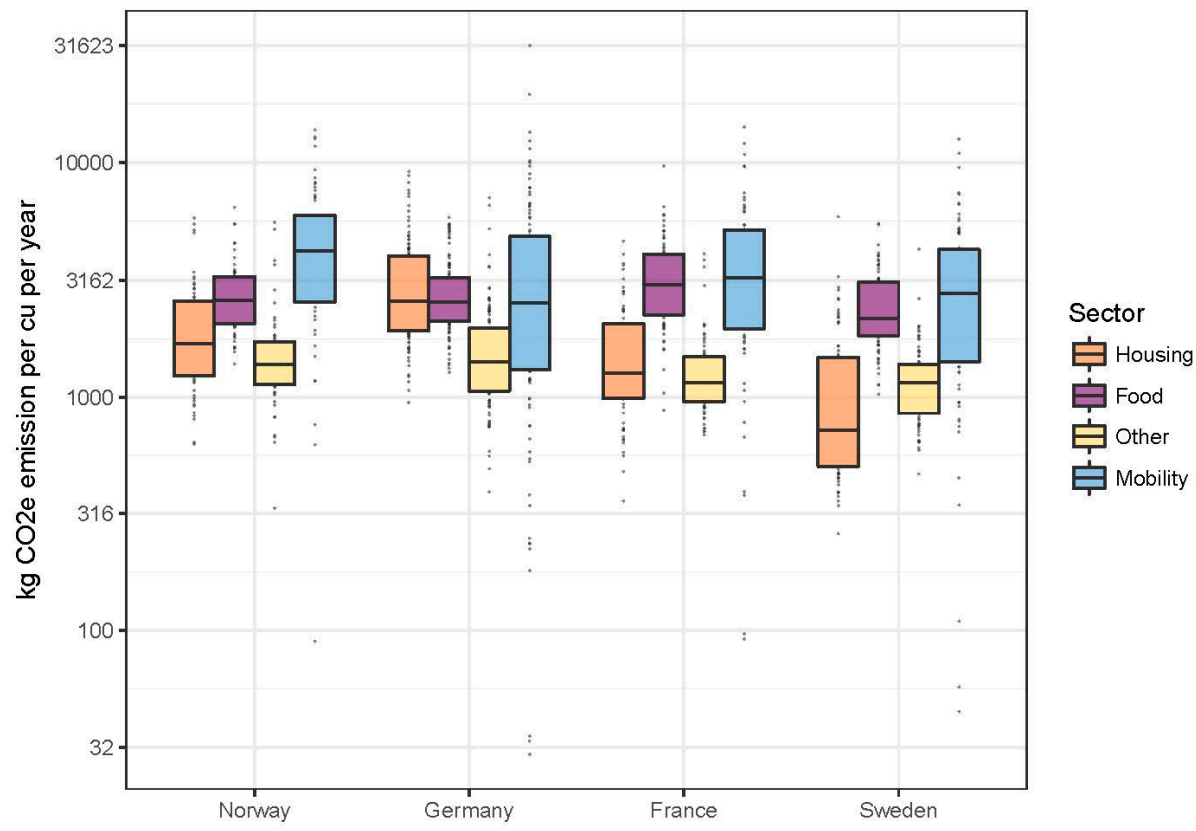

Figure 1. GHG emission per country and household sector of consumption $\left(\mathrm{CO}_{2}\right.$ equivalents per consumption unit per year). The colored boxes show the distribution range between the 0.25 and 0.75 quantiles $(0.25 ; 0.5$; and 0.75$)$ for each household sector by country. The middle bars indicate the median values. Dots represent values for individual households outside the 2 nd to 3 rd quantile range. The scale on the $y$-axis is logarithmic.

\subsection{Carbon Footprint Reduction in the two Scenarios of the Simulation Game}

Figure 2 (see Table S1 (Supplementary Materials: Tables Spreadsheet) for detailed information) presents the reductions of the baseline CF in the two rounds of the simulation game ( $\operatorname{Sim} 1$ and Sim2) for the four household sectors. The median baseline CF for the 308 households was reduced by $25 \%$, from around 9.5 tons of $\mathrm{CO}_{2}$ e per $\mathrm{CU}$ per year to 7.1 after the voluntary scenario Sim1. The 'voluntary' scenario Sim 1 resulted in a cross-country median decrease of $34 \%$ in the food sector, $29 \%$ for housing, $26 \%$ for mobility, and $8 \%$ for other consumption. The variation between the studied countries' reduction was minor (see Table S8 (Supplementary Files: Tables spreadsheet)) During the forced scenario (Sim2), most households reached, or came very close in reaching, the reduction target of $50 \%$. The few exceptions occurred because the households started with an already low baseline $\mathrm{CF}$, which made it technically impossible to reach the target due to lack of available action cards. The 'forced' scenario Sim 2 resulted in a median reduction of $48 \%$ of the total baseline CF (food: $56 \%$, housing: $49 \%$, mobility: 59\%, other: $14 \%$ ). In the food sector more than half of households' total reductions (56\%) was made during the voluntary scenario (36\% in Sim 1, 20\% in Sim2). In the mobility sector, more than half of their total reduction $(59 \%)$ was made during the forced scenario $(26 \%$ in $\operatorname{Sim} 1,33 \%$ in $\operatorname{Sim} 2)$. Substantial $\mathrm{CO}_{2}$ e reductions in the mobility sector during $\mathrm{Sim} 2$ were due to the yearly $\mathrm{CO}_{2} \mathrm{e}$ reductions in the commodities Plane (53\%) and Car (70\%) travel. In the housing sector households' reductions in Sim 2 were primarily caused by cutting their consumption of the commodity Heating by 76\% (see Tables S2 and S5 (Supplementary Files: Tables spreadsheet)). 


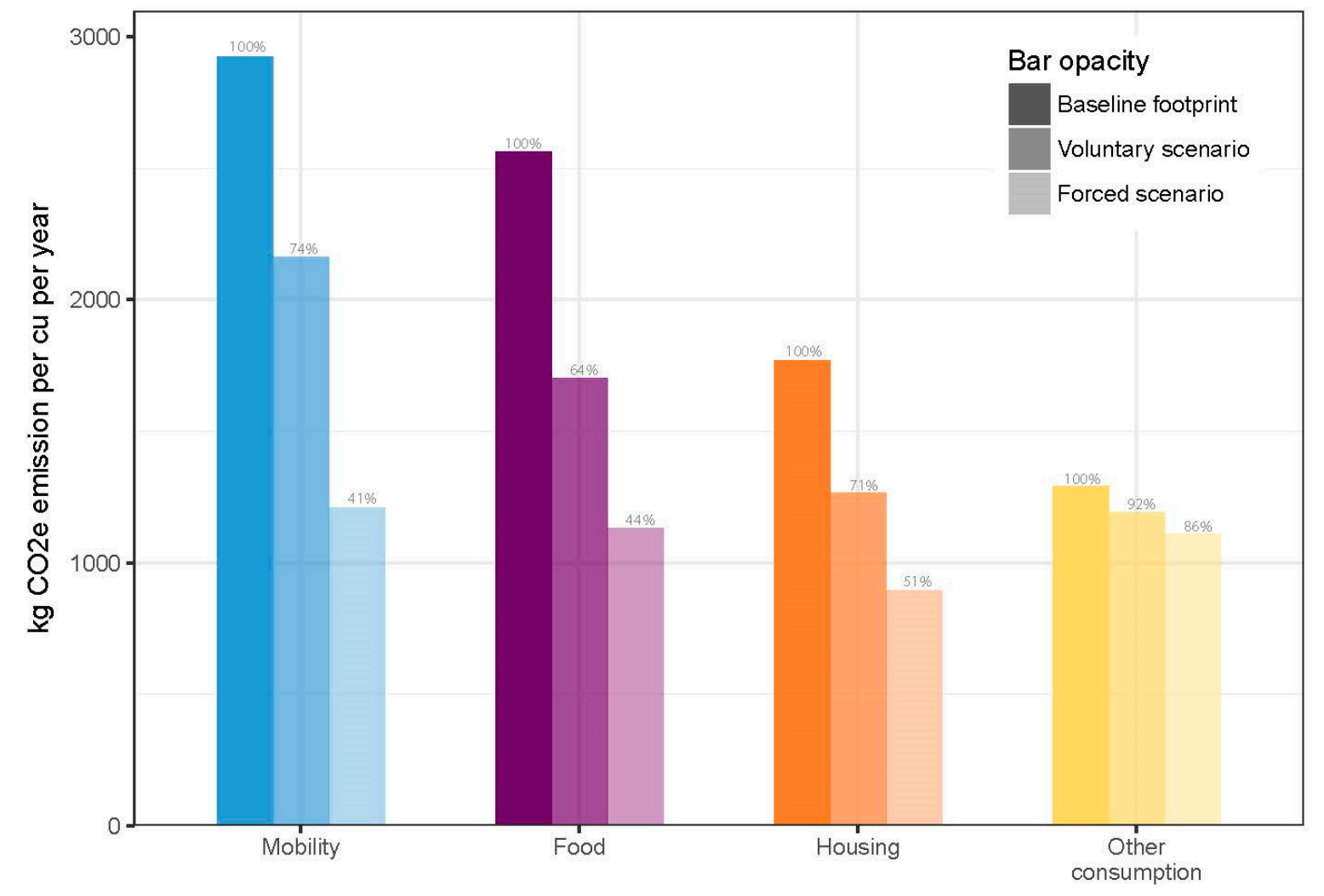

Figure 2. Median $\mathrm{CO}_{2} \mathrm{e}$ emissions at baseline and after the simulation game by household sectors. The opacity of the bars represents the three stages of the simulation game; baseline carbon footprint (CF), the Voluntary scenario CF, and the Forced scenario CF. The bars are grouped and colored by household sectors. The unit of measurement is in $\mathrm{kg} \mathrm{CO}_{2}$ e per consumption unit per year. The percentage over each bar represent the observed median levels of CF for each stage in relation to the baseline CF.

\subsection{Reduction Potential and Mitigation Choices}

In this chapter, action cards chosen during the voluntary scenario (Sim1), and/or during the forced scenario (Sim2) are described as, for example, Insulate roof/attic (Sim1: 30\%, Sim2: 52\%). This translates as follows: In Sim1, 30\% of the households who had the possibility to choose this action, chose it. After Sim 2, 52\% of the households that had the possibility to choose this action, had chosen it either during Sim1 or during Sim2.

Figure 3 shows the number of households that either: Chose an action during Sim1 (light blue), chose an action during Sim2 (mid blue), did not chose the available action (grey), could not chose the action either because they already did it (red), or because it was not applicable (black). Figure 3 shows actions ranked by decreasing "popularity" based on selection in Sim1. Furthermore, in the right-hand panel it depicts the corresponding median $\mathrm{CO}_{2}$ e reduction potential per action across households. Actions H3.2 and H3.6 were not included because they were applicable to less than $10 \%$ (i.e., $n<31$ ) of the households. A frequency table with complementary information is found here (Supplementary Materials: S2 spreadsheet).

Out of the top ten most chosen actions, half were linked to food. However, out of the top ten actions with highest reduction potential, half were linked to mobility, the sector that yielded most emissions and thus had the highest reduction potential. During the voluntary scenario (Sim1) none of the ten actions with highest reduction potential could be allocated amongst the $50 \%$ most chosen. Amidst the top 20 most chosen actions, half were linked to food and none had high reduction potential. These 20 actions combined would yield a GHG reduction of around 2 tons per CU per year, less than enough to reach the $50 \%$-target for most households. The most popular action was Buy products with less or greener packaging (Sim1: 65\% and Sim2: 82\%) which together with the second most 
chosen-Recycle 30\% more of your waste-(Sim1: $63 \%$, Sim2: $90 \%$ ), both food commodities, had a combined reduction potential of around 0.2 tons $\mathrm{CO}_{2} \mathrm{e}$ for a typical household. However, $64 \%$ of all households already recycled $>90 \%$ of their waste and could thus not choose that action card. Amongst the least chosen actions, i.e., the bottom 20 (ordered after Sim1 result), the patterns were alike amid the four countries. The foremost finding was that the actions least chosen in all countries were very similar: Become a vegetarian ... (Sim1: 4\%, Sim2: 17\%), Give up your $\operatorname{car}(\mathrm{s})(\operatorname{Sim} 1: 4 \%$, Sim2: 21\%) etc., reduce your flights [both European and international] by 90\% (Sim1: 9\%, Sim2: 50\%), and most of the "Shift heating system"-actions (Sim1: 8-14\%, Sim2: 20-22\%) were bottom 15 in all countries. Most of these actions had high reduction potentials around and above half a ton $\mathrm{CO}_{2}$ e per $\mathrm{CU}$ per year each. Regarding the action cards connected hot heating systems however, many households were found incapable of choosing these because they were renting an apartment that rendered the actions inapplicable.

Overall, a negative association was found during the voluntary scenario (Sim1) between the frequency of chosen actions and their reduction potential (beta $=-0.029, P=0.018$ ). During the forced scenario (Sim2), the association was not present (beta $=0.018, P=0.297$ ). Stratifying on household sectors, the association was mainly present in mobility and housing in $\operatorname{Sim} 1$ (beta $=-0.071, P=0.006$ and beta $=-0.054, P=0.006$ respectively). In Sim2, the null association was present in all sectors except in other consumption, where a positive association between chosen actions and reduction potential was observed (beta $=0.087, P=0.034$ ) (see Table S9 (Supplementary Materials: Tables spreadsheet)). 


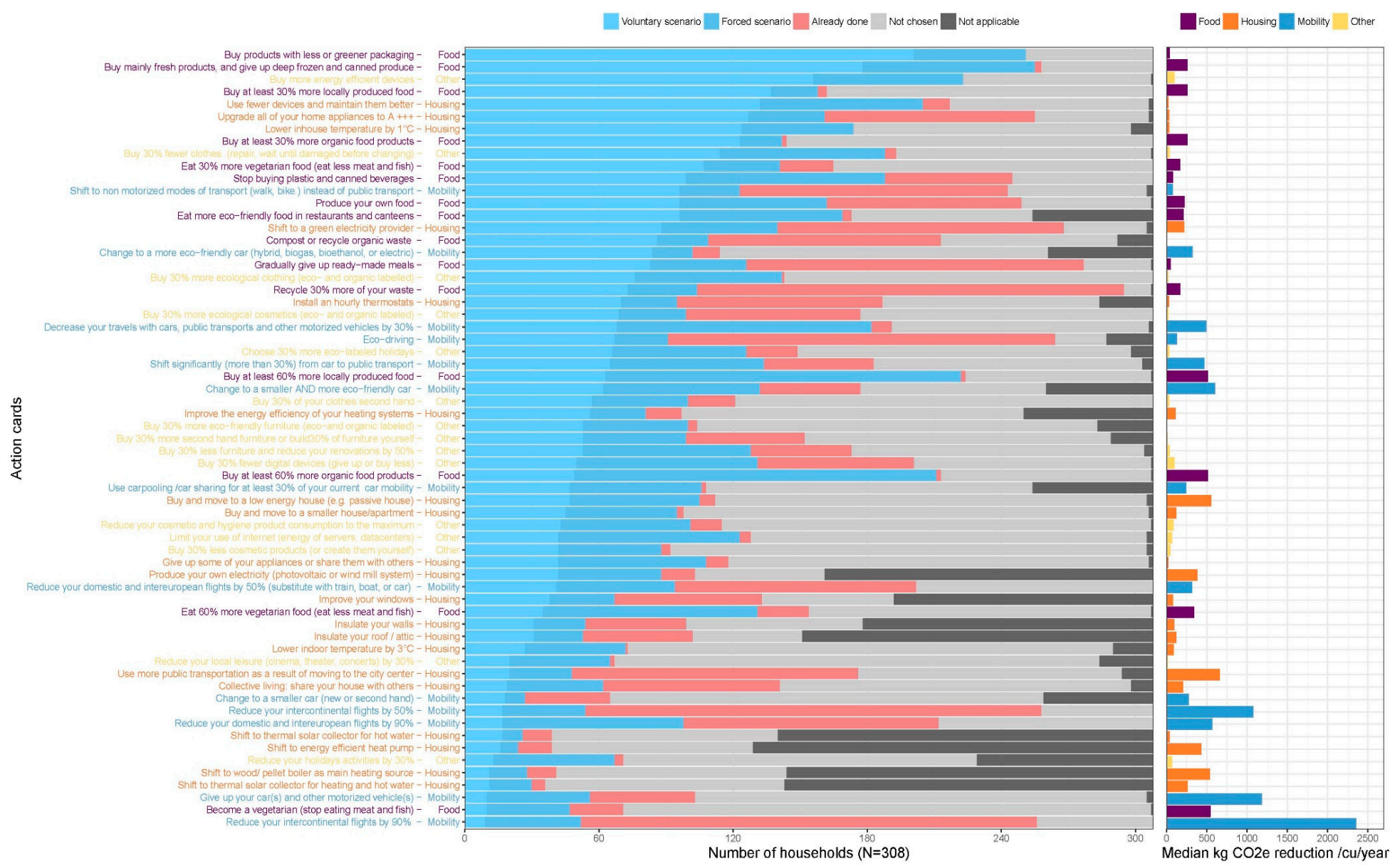

Figure 3. Households' choices of action cards during the simulation game and the $\mathrm{CO}_{2} \mathrm{e}$ reduction potential for each action. Listed on the $y$-axis are the 63 action cards that participants could select. The left-hand panel shows: 1. Chosen actions in Sim1 (light blue), 2. Chosen actions in Sim2 (mid blue), 3. Actions that could not be chosen because the households already did this action—information provided in the questionnaire or during the interview—(red), 4. Applicable actions that were not chosen (grey), and 5. Inapplicable actions that were not possible to choose because of technical reasons (Black). The right-hand panel shows median reduction potential in $\mathrm{kg} \mathrm{CO}_{2}$ e per $\mathrm{CU}$ per year (excluding already done, and not possible actions). The bars are colored to represent the households' four consumption sectors: housing (orange), food (purple), mobility (blue), and other (orange). 
The pattern "the more popular the action, the less $\mathrm{CO}_{2} \mathrm{e}$ reduction potential" as depicted for the voluntary scenario in Figure 4, can be illustrated by example: Amongst the households that had the possibility to choose these actions, eco-driving was the most popular mobility measure, and buying an eco-friendlier car was chosen by $34 \%$ of households, yet only $4 \%$ were ready to give up their private car. Moreover, $38 \%$ of the households were willing to eat $30 \%$ more vegetarian food, but only $4 \%$ chose to become a vegetarian.

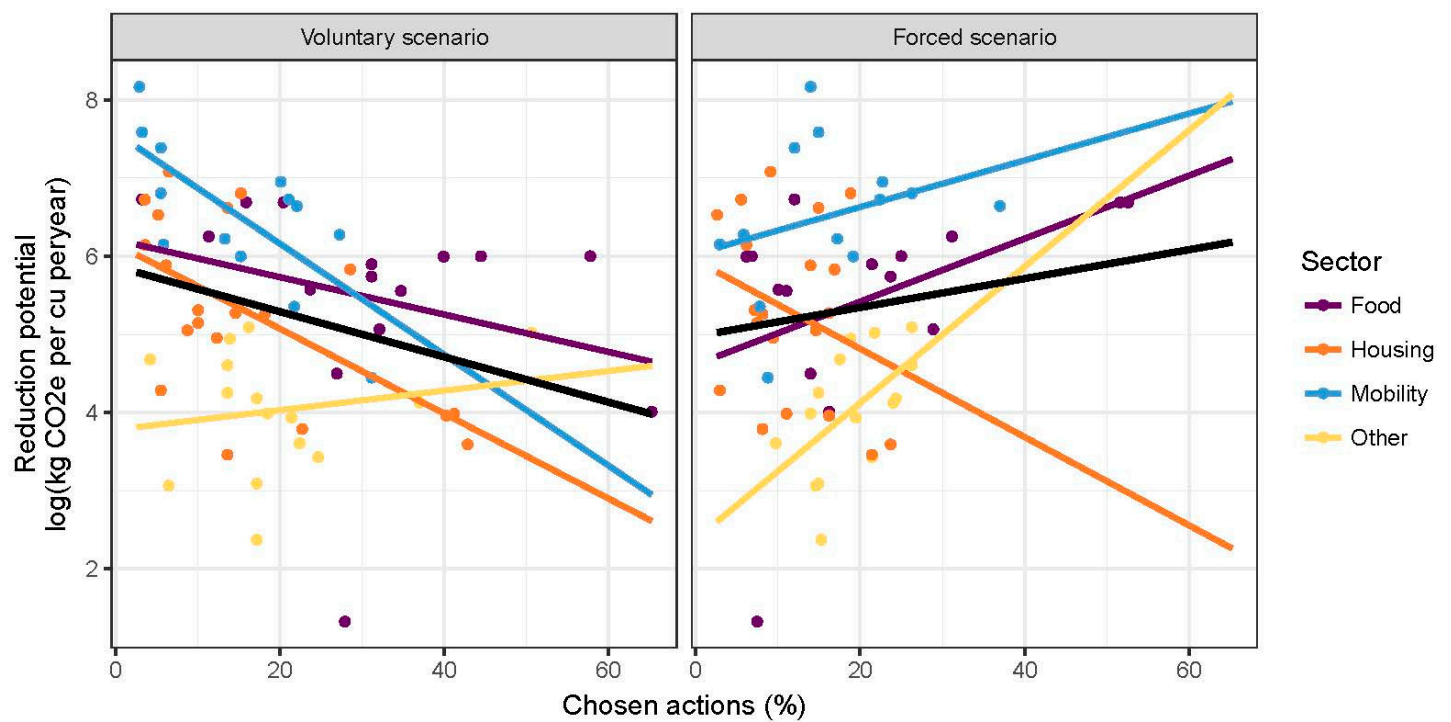

Figure 4. Regression-Reduction potential vs. Chosen action cards. Associations between log-transformed Reduction potential $\left(\mathrm{kg} \mathrm{CO}_{2} \mathrm{e}\right.$ per $\mathrm{CU}$ per year) and chosen actions (frequency of households that selected the action card) in the voluntary scenario (Sim1) and forced scenario (Sim2) stratified by household sector. The black line represents a linear regression line fitted in all sectors. The colored lines represent linear regression lines fitted within each sector.

The median $\mathrm{CO}_{2}$ e reductions in the right-hand panel in Figure 3 shows that many households would just have had to choose the top three action cards with the biggest reduction potential-reduce your intercontinental and European flights by $90 \%$, and give up your car(s) and other motorized vehicle(s) - to reach the $50 \%$ reduction target. By choosing these three actions, a household would have reduced their $\mathrm{CF}$ by around 4.6 tons $\mathrm{CO}_{2} \mathrm{e}$ per $\mathrm{CU}$ per year. Less, and around $20 \%$, chose either of the two flight-related action cards during the voluntary scenario (Sim1), but when 'forced' to reach the 50\% target during Sim 2 half of all households had chosen either " $-90 \%$ flights intercontinental" or " $-90 \%$ flights Europe". Furthermore, two thirds of the participating household had not taken any intercontinental flights in the last two years, and one third had taken no European flights. These households, therefore, did not have the option to reduce their plane-based emission, instead captured in the category "already done" (see Figure 3).

A strong association was found between baseline $\mathrm{CF}$ and household income per consumption unit (see Figure 5). However, to illustrate the differences between households with low and high reduction potential and their choices of action cards, the population was split into quintiles of baseline CF by subcategories illustrated in Table S10 (Supplementary Materials: Tables spreadsheet). 


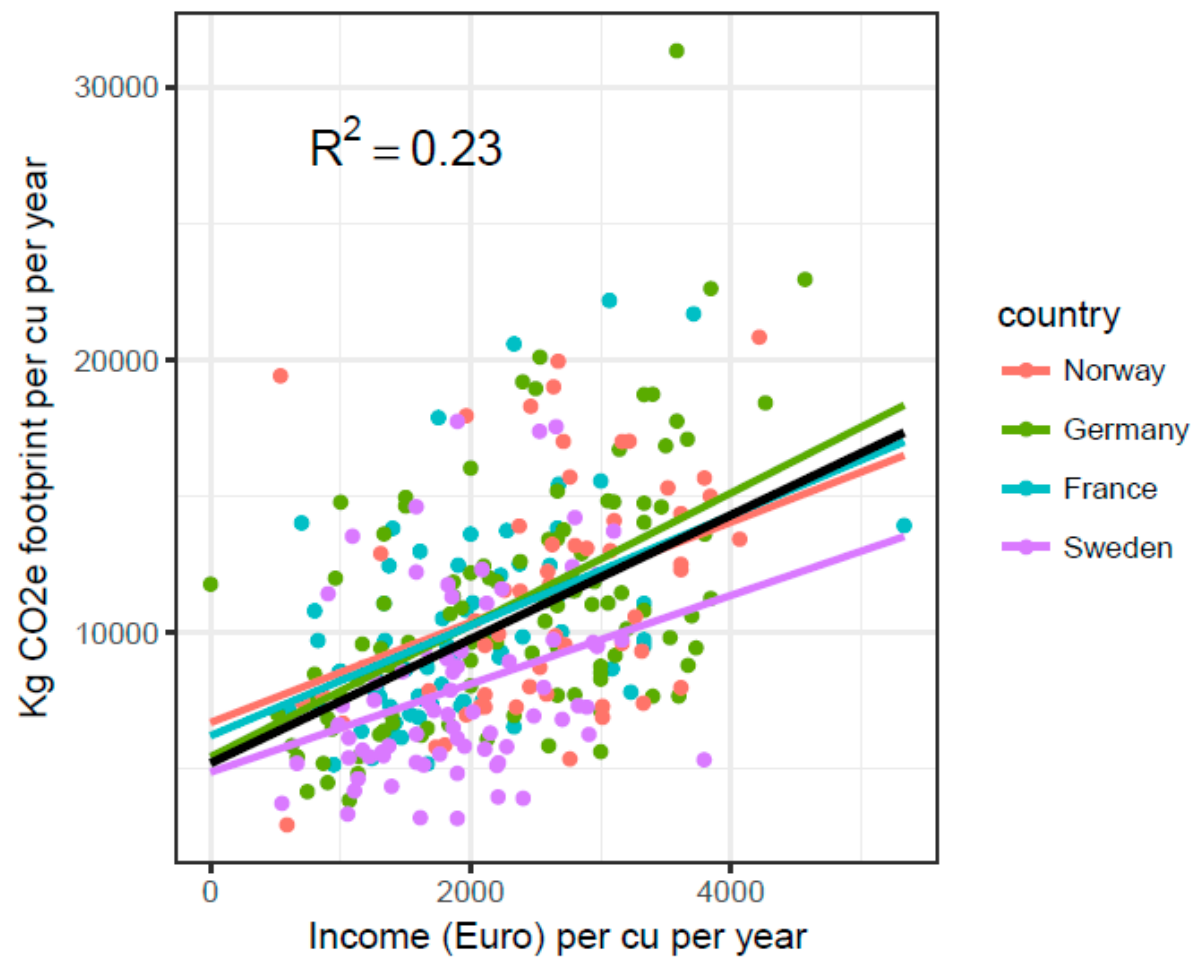

Figure 5. Association between household carbon footprint at baseline ( $\mathrm{kg} / \mathrm{CO}_{2}$ per CU per year) and household yearly income (converted to $\mathrm{CU}$ ). The black line represent a regression line fitted in all countries, colored lines were fitter within each country.

\subsection{Patterns between low- and high Emitting Households Regarding Three Essential Mitigation Commodities}

Table S10 (Supplementary Files: Tables Spreadsheet) shows the reduction potential for action cards related to the commodities Plane, Car and Meat consumption, the three items isolated in this study as particularly important for household mitigation based on their high reduction potential.

The baseline CF scores showed a wide discrepancy between quintiles in mobility and food. For instance, the commodity plane's median $\mathrm{CO}_{2} \mathrm{e}$ emissions per consumption unit and year ranged from zero tons in the first quintile to 3941 tons in the fifth quintile, whereas the range for meat and fish consumption reached from 328 to 675 tons in the first and fifth quintile. The share that the commodities car and plane contributed to baseline CF in mobility was immense (up to $85 \%$ ), however less so regarding fish and meat (less than 30\%). The reduction potential i.e., the maximum amount of $\mathrm{CO}_{2} \mathrm{e}$ that could be mitigated by choosing action cards (median values) followed similar patterns to that of the baseline variables.

The observed reductions $\left(\mathrm{kg} \mathrm{CO}_{2}\right.$ e per $\mathrm{CU}$ per year) from the voluntary scenario (Sim1) showed median values of zero in all quintiles for plane, which implies that these actions were unpopular even though the reduction potential was substantial. A small and incremental increase in reductions between Q1-Q5 was observed for car, with the exception of Q4. Meat and fish reductions held the highest reduction potential for low-mitigating households in absolute numbers, but showed little reductions in the voluntary scenario. However, the low-emitting households (Q1-Q3) reduced their meat consumption more than the high-emitting households (Q4-Q5).

The forced scenario (Sim2) yielded high reductions in plane and car, as well as in fish and meat. In absolute values, a clear increase in reductions was observed the higher the quintile for all variables during Sim2. However, for car and plane, the observed reductions, relative to baseline values and reduction potential, showed an opposite pattern where the lowest quintile (Q1) reduced twice as much as the highest quintile (Q5). Regarding meat and fish, on the other hand, the higher the quintile, the more households mitigated both in absolute and relative terms in relation to the reduction potential and baseline values. 
Lastly, the total reduction (all 63 variables included) achieved by households during both simulations did not vary much between quintiles (20-28\%) after Sim1 and (46-50\%) after Sim2, however, in absolute values ( $\mathrm{kg} \mathrm{CO} 2 \mathrm{e}$ per CU per year) the differences between Q1 and Q5 were considerable e.g., If Q5 would have mitigated as much, in percent, as Q1, they would have reduced their CF by an additional $800 \mathrm{~kg} \mathrm{CO} 2 \mathrm{e}$ per CU year (see Table S11 (Supplementary Materials: Tables spreadsheet)).

In conclusion, low emitting households reduced more of their household's emissions than the high emitting households, with the exception of meat and fish consumption.

\section{Discussion}

\subsection{Discussion of Results}

In this novel empirical study, by applying serious gaming (SG) techniques, households were confronted with an ambitious $\mathrm{CO}_{2}$ reduction target to analyze their preferences to undertake GHG emission reductions in their everyday life. We found that when participants were faced with the task to reduce their emissions by $50 \%$ before 2030 - on a voluntary basis - they managed to reduce $25 \%$ of their baseline CF predominantly by reductions from actions that would not greatly affect their current way of life. This included actions such as buying food products with greener packaging that were more locally produced and organic grown, buying more electric-efficient devices, and upgrading their home appliances to conserve energy consumption. As suggested by Capstick et al. [25], this could be due to major implications on their current lifestyle that they were reluctant to change. In the second scenario, when participants were forced to reach a $50 \%$ reduction, a clear change of pattern in households' choices of action cards was observed. Households began to choose actions that implied "giving up" certain consumption patterns (e.g., reducing their flights, giving up their car), i.e., making substantial lifestyle changes thus reducing consumption volume. It is important to mention that even though the voluntary scenario depicts a more realistic situation than the forced, the latter gives an idea of what sturdy policy making could achieve if implemented accordingly.

To achieve the global climate goals to keep global warming well below $2{ }^{\circ} \mathrm{C}$, considerable lifestyle changes are needed. Changing the patterns and levels of private consumption has the potential to significantly reduce GHG emissions, especially when targeting the areas of mobility, housing, diet, and waste [32]. To reach the 1.5 degree goals, and at the same time avoid being dependent on large-scale implementation of negative-emission technologies [33], consumption related emissions will have to be addressed to a much greater extent in national climate mitigation policies. As stated by Moberg and colleagues, "Policy efforts in this field tend to individualize responsibility for an issue that, due to the magnitude of the problem, is difficult to address in the absence of coordinated collective action" [13]. However, the nature and extent of moral obligations resting on the shoulders of individuals to take specific mitigation actions are unclear [34]. There is also a question to be raised if the current focus in the consumption related part in climate policymaking, with a strong focus on voluntary actions, are effective- to the extent that it also is uncertain whether individual actors are willing to take on responsibility to act voluntarily on mitigation at any substantial rate [13].

For instance, this study has found that regardless of the city investigated, people did not willingly give up flying even though it was the single most effective way for them to mitigate. Moreover, households were reluctant to give up their car and to reduce their meat consumption. The latter showed a clear discrepancy between levels of reduction where reducing meat consumption by $30 \%$ was willingly chosen by over a third of all participants, whereas 'become a vegetarian' was chosen by less than $5 \%$. In other contexts, studies have showed similar results [35,36], and given the procedure of the simulation game these results now manifest additional credibility to these findings.

Furthermore, the assumption that people lack motivation to substantially change their behavior regarding mobility and diet for environmental reasons has been widely studied and confirmed [37-41]. Yet, households in this study were willing to implement moderate changes, especially related to food. 
During the simulation game, many small changes in combination could have resulted in relatively high $\mathrm{CO}_{2} \mathrm{e}$ reductions if chosen together.

Our result showed that the higher the action card's reduction potential was the less willing households were to implement it. This suggests that under current circumstances, households are unlikely to contribute substantially to climate change mitigation on a voluntary basis. This paradox is attained foremost by the results seen in mobility and housing; the sectors with the lowest frequency of chosen action cards during the voluntary scenario. The negative association found between chosen mitigation actions and reduction potential manifests this paradox and highlights the issues embedded within concepts such as "behavior change", "consumer power", or "citizen-consumer [42]". Issues that—as argued by Barr et al. [37,43,44]-lack substantial effect in adjusting lifestyles to cope with climate change. Moreover, studies have pointed out that consumption based emission patterns tend to be connected to households' income, and lifestyle behaviors $[7,38]$. The idea that high income households also hold higher emission levels aligned well with the scope of this study, why it was decided to focus on the "choices of mitigation" related to this phenomenon. The approach to analyze low emitting households' mitigation actions versus the high emitting households' instead of high/low income households intended to broaden the spectrum of research in this field. In retrospect, it could be argued that the results would have turned out similar anyway due to the fact that household emission and income were found to be strongly correlated. Regarding the three items of investigation (plane, car, and meat) in the quintile assessment, we can conclude that already low-emitting households were relatively more willing to mitigate GHG emission on a voluntarily basis, among which, mitigation actions connected to meat consumption, were found to be the most chosen. These findings encourage the idea of diversified policymaking for different GHG emission groups of households, where low emitting households would be fit for reductions in meat consumption, while gradually implementing mobility mitigation actions. High emitting households would need to take on a bigger role beginning with their car usage, followed by meat consumption. Lastly, the importance of reducing emissions from private flights has to be stressed. The willingness to mitigate mobility as such was found to be low in our investigated European cities, especially for international flights. However, since more than one third of our investigated households had no registered inter-European/domestic, and around two thirds had no intercontinental flights in the last two years, it could be argued that they already have mitigated in this area. These results raises an important issue namely: Could people cope with a plane-free private lifestyle? Local and European policymakers should address this, by supporting further research in this area, and by advocating alternatives to the plane by, for example, implementing regulations in the flight sector, subsidies to low-emission alternatives, and information campaigns.

\subsection{Discussion of Methods}

This study adds to previous research on $\mathrm{CO}_{2} \mathrm{e}$ mitigation since it (a) analyses household consumption and its associated $\mathrm{CO}_{2} \mathrm{e}$ emissions in the particular context of emission trajectories compatible with the $1.5^{\circ} \mathrm{C}$ goal; (b) uses the techniques of "serious gaming" (see Section 2) to understand how households may change their consumption in order to achieve specified $\mathrm{CO}_{2} \mathrm{e}$ reduction targets; and (c) differ between an initial voluntary and a subsequent forced scenario that indicate the amount of policy support the two groups of actions need to receive for initiating effective household mitigation behavior. By following individual households through these steps of interventions, data has been collected that provides insight into mitigation behavior unique of its kind.

Participants had to handle a lot of information by receiving up to 65 mitigation actions that included information on costs, $\mathrm{CO}_{2} \mathrm{e}$ reduction potential and in some cases health impact, which risked their choices being made less carefully $[45,46]$. However, the serious gaming techniques has great potential for understanding and influencing the behavior and performance of individuals in such context [47]. Even though the process took some time (around two hours), this was likely necessary for the participant's choices to be well balanced and carefully considered. A minor point is that the responses to the action cards in such scenarios can be highly dependent on the wording of the options: 
For example, Lea et al. [40] reported that language less associated with personality change e.g., 'switch to a plant-based diet instead of 'become a vegetarian' can effect participants choices. Similarly, other studies have pointed out that barriers involved with mitigation and behavior change are more easily overcome by gradual changes rather than strict prohibitions and abrupt lifestyle changes [41].

Furthermore, imposing a scenario which forced participants to reach a $50 \%$ reduction target could inherit some limitations, foremost that participants "just chose" actions, not considering the implications this would have in their life, other than lowering their carbon footprint. Thus, the quantitative data from the forced scenario might depend on other factors than households' actual behavior and preferences to mitigate, but has nevertheless provided interesting findings about what a " $1.5^{\circ} \mathrm{C}$ lifestyle" would require.

Lastly, the baseline $\mathrm{CF}$ of the four investigated cities (median of 9.5 tons $\mathrm{CO}_{2}$ e per $\mathrm{CU}$ per year) was in line with existing research conducted on similar bases as this study [17,48,49], however, with some differences between the cities attained foremost by characteristics in energy production (e.g., sources of electricity and heating that yield different GHG emission in baseline values). Differences, as such, arise when pooled data is used from different cities and can be very useful for policy recommendations, however since the different cities' households went through this study in their separate context, the descriptive overview presented in this study did not analyze implications specifically.

\section{Conclusions}

In this study, we found that individuals were less likely to undergo lifestyle changes with large effects on their current carbon emission levels (e.g., less flying or meat consumption). This suggests that public policies need to focus at making households reduce their private carbon emission intense consumption in order to reach EUs 1.5, and $2{ }^{\circ} \mathrm{C}$ target. Participants in this this study chose their actions rationally and expectedly, as previous research has pointed out by first reaching for the "low hanging fruit". They would not voluntarily mitigate GHG emissions by more than $25 \%$, but will likely be able to go this far provided appropriate incentives. To adjust for the diversities among low/high-emitting households and their different mitigation preferences, stakeholders should look for systems that take this into consideration such as, for example, policies adjusted for household emission levels, and demographics. Based on the results in this study, it can be concluded that policies need to specifically focus at making households-by means of facilitating collective actions-reduce their consumption volume of private flights, car usage, and meat consumption in order to reach EUs 1.5 , and $2{ }^{\circ} \mathrm{C}$-target, while at the same time keep supporting households with policies that increases incentives to improve the efficiency of their everyday consumption.

Supplementary Materials: All supplementary materials are available online at http:/ /www.mdpi.com/20711050/10/11/4044/s1.

Author Contributions: Conceptualization of the HOPE study design, all authors; Conceptualization of the present paper, B.S.; Data acquisition, B.S., M.B., C.A. (Camilla Andersson), S.B., A.H.; Data curation, B.S. and M.B.; Formal analysis, B.S.; Funding acquisition, M.N.; Methodology, B.S. and M.B.; Project administration, A.H. and R.S.; Supervision, M.N.; Validation, M.B.; Visualization, B.S.; Writing-original draft, B.S. and M.B.; Writing-review \& editing, B.S., C.A. (Carlo Aall), C.A. (Camilla Andersson), A.H., D.A., C.B., M.N. and R.S.

Funding: This paper was written in the framework of the JPI Funded project HOPE (Household preferences for reducing greenhouse gas emissions) www.hope-project.net. The presented research project is supported by national funding bodies under the umbrella of the Joint Program Initiative (JPI) Climate, a Pan-European intergovernmental initiative. In particular, the following national funding agencies are funding this research: The French National Research Agency (ANR-14-JCLI-0001-03), the German Federal Ministry of Education and Research (01UV1414A), the Research Council of Norway $(244,905 / E 10)$ and the Swedish Research Council for Environment, Agricultural Sciences and Spatial Planning (214-2014-1717).

Acknowledgments: We especially want to thank the households for their patience and the care with which they answered to our many questions. Special thanks to the colleagues at Umea University; R. Myte and W. Prentius for their tech. skills and support.

Conflicts of Interest: The authors declare no conflict of interest. 


\section{References}

1. Pachauri, R.K.; Mayer, L.; Intergovernmental Panel on Climate Change. (Eds.) Climate Change 2014: Synthesis Report; Intergovernmental Panel on Climate Change: Geneva, Switzerland, 2015.

2. United Nations Framework Convention on Climate Change (UNFCCC). 2030 Climate \& Energy Framework, Klimat-European Commission. 23 November 2016. Available online: https:/ / ec.europa.eu/clima/policies/ strategies/2030_en (accessed on 10 November 2017).

3. Intergovernmental Panel on Climate Change (IPCC). 2.10.2 Direct Global Warming Potentials-AR4 WGI Chapter 2: Changes in Atmospheric Constituents and in Radiative Forcing. 2013. Available online: https: //www.ipcc.ch/publications_and_data/ar4/wg1/en/ch2s2-10-2.html (accessed on 10 November 2017).

4. Aall, C.; Hille, J. Consumption-A missing dimension in climate policy. In Interdisciplinarity and Climate Change; Transforming Knowledge and Practice for Our Global Future; Bhaskar, R., Frank, C., Hoyer, K.G., Naess, P., Parker, J., Eds.; Routledge: London, UK, 2010; pp. 85-100.

5. Riahi, K.; Dentener, F.; Gielen, D.; Grubler, A.; Jewell, J.; Klimont, Z.; Krey, V.; McCollum, D.; Pachauri, S.; Rao, S.; et al. Energy pathways for sustainable development. In Global Energy Assessment-Toward a Sustainable Future; Cambridge University Press: Cambridge, UK; New York, NY, USA; International Institute for Applied Systems Analysis: Laxenburg, Austria, 2012; pp. 1203-1306.

6. Riahi, K.; van Vuuren, D.P.; Kriegler, E.; Edmonds, J.; O’Neill, B.C.; Fujimori, S.; Bauer, N.; Calvin, K.; Dellink, R.; Frick, O.; et al. The Shared Socioeconomic Pathways and their energy, land use, and greenhouse gas emissions implications: An overview. Glob. Environ. Chang. 2017, 42, 153-168. [CrossRef]

7. Piketty, T. The Economics of Inequality; Harvard University Press: Cambridge, MA, USA, 2015.

8. Tukker, A.; Cohen, M.J.; Hubacek, K.; Mont, O. The Impacts of Household Consumption and Options for Change. J. Ind. Ecol. 2010, 14, 13-30. [CrossRef]

9. Zhang, X.; Luo, L.; Skitmore, M. Household carbon emission research: An analytical review of measurement, influencing factors and mitigation prospects. J. Clean. Prod. 2015, 103, 873-883. [CrossRef]

10. Le Quéré, C.; Andrew, R.M.; Friedlingstein, P.; Sitch, S.; Pongratz, J.; Manning, A.C.; Korsbakken, J.; Peters, G.P.; Canadell, J.G.; Jackson, R.B.; et al. Global Carbon Budget 2017. Earth Syst. Sci. Data Discuss. 2018, 10, 405-448. [CrossRef]

11. Jackson, R.B.; le Quéré, C.; Andrew, R.M.; Canadell, J.G.; Peters, G.P.; Roy, J.; Wu, L. Warning signs for stabilizing global $\mathrm{CO}_{2}$ emissions. Environ. Res. Lett. 2017, 12, 110202. [CrossRef]

12. Ivanova, D.; Vita, G.; Steen-Olsen, K.; Stadler, K.; Melo, P.C.; Wood, R.; Hertwich, E.G. Mapping the carbon footprint of EU regions. Environ. Res. Lett. 2017, 12, 054013. [CrossRef]

13. Moberg, K.R.; Aall, C.; Dorner, F.; Reimerson, E.; Ceron, J.; Sköld, B.; Sovacool, B.K.; Piana, V. Mobility, food and housing: Responsibility, individual consumption and demand-side policies in European deep decarbonisation pathways. In Energy Efficiency; Springer: Berlin, Germany, 2018.

14. Dietz, T.; Gardner, G.T.; Gilligan, J.; Stern, P.C.; Vandenbergh, M.P. Household actions can provide a behavioral wedge to rapidly reduce US carbon emissions. Proc. Natl. Acad. Sci. USA 2009, 106, 18452-18456. [CrossRef] [PubMed]

15. Dubois, G.; Ceron, J.-P. Consommation et modes de vie: Une autre perspective sur les politiques d'atténuation du changement climatique. Nat. Sci. Soc. 2015, 23, S76-S90. [CrossRef]

16. Bjelle, E.L.; Steen-Olsen, K.; Wood, R. Climate change mitigation potential of Norwegian households and the rebound effect. J. Clean. Prod. 2018, 172, 208-217. [CrossRef]

17. Hertwich, E.G.; Peters, G.P. Carbon Footprint of Nations: A Global, Trade-Linked Analysis. Environ. Sci. Technol. 2009, 43, 6414-6420. [CrossRef] [PubMed]

18. Ivanova, D.; Stadler, K.; Steen-Olsen, K.; Wood, R.; Vita, G.; Tukker, A.; Hertwich, E.G. Environmental Impact Assessment of Household Consumption. J. Ind. Ecol. 2016, 20, 526-536. [CrossRef]

19. Peters, G.P.; Minx, J.C.; Weber, C.L.; Edenhofer, O. Growth in emission transfers via international trade from 1990 to 2008. Proc. Natl. Acad. Sci. USA 2011, 108, 8903-8908. [CrossRef] [PubMed]

20. Semenza, J.C.; Hall, D.E.; Wilson, D.J.; Bontempo, B.D.; Sailor, D.J.; George, L.A. Public Perception of Climate Change. Am. J. Prev. Med. 2008, 35, 479-487. [CrossRef] [PubMed]

21. Lorenzoni, I.; Nicholson-Cole, S.; Whitmarsh, L. Barriers perceived to engaging with climate change among the UK public and their policy implications. Glob. Environ. Chang. 2007, 17, 445-459. [CrossRef] 
22. Whitmarsh, L. Behavioural responses to climate change: Asymmetry of intentions and impacts. J. Environ. Psychol. 2009, 29, 13-23. [CrossRef]

23. Gatersleben, B.; Steg, L.; Vlek, C. Measurement and determinants of environmentally significant consumer behavior. Environ. Behav. 2002, 34, 335-362. [CrossRef]

24. Girod, B.; van Vuuren, D.P.; Hertwich, E.G. Climate policy through changing consumption choices: Options and obstacles for reducing greenhouse gas emissions. Glob. Environ. Chang. 2014, 25, 5-15. [CrossRef]

25. Capstick, S.; Lorenzoni, I.; Corner, A.; Whitmarsh, L. Prospects for radical emissions reduction through behavior and lifestyle change. Carbon Manag. 2014, 5, 429-445. [CrossRef]

26. Abrahamse, W.; Steg, L.; Vlek, C.; Rothengatter, T. A review of intervention studies aimed at household energy conservation. J. Environ. Psychol. 2005, 25, 273-291. [CrossRef]

27. Herrmann, A.; Fischer, H.; Amelung, D.; Litvine, D.; Aall, C.; Andersson, C.; Baltruszewicz, M.; Barbier, C.; Bruyère, S.; Bénévise, F.; et al. Household preferences for reducing greenhouse gas emissions in four European high-income countries: Does health information matter? A mixed-methods study protocol. BMC Public Health 2018, 18, 71. [CrossRef] [PubMed]

28. Bruyère, S.; Dubois, G.; Baltruszewicz, M.; Ceron, J.P.; Skold, B.; Andersson, C.; Louis, V.R.; Sorgho, R.; Barbier, C. A Dynamic and generic household carbon footprint calculator to simulate mitigation choices for households. 2018, in press.

29. Sanderson, B.M.; O'Neill, B.C.; Tebaldi, C. What would it take to achieve the Paris temperature targets? Geophys. Res. Lett. 2016, 43, 7133-7142. [CrossRef]

30. Rogelj, J.; Luderer, G.; Pietzcker, R.C.; Kriegler, E.; Schaeffer, M.; Krey, V.; Riahi, K. Energy system transformations for limiting end-of-century warming to below $1.5^{\circ} \mathrm{C}$. Nat. Clim. Chang. 2015, 5, 519-527. [CrossRef]

31. Eurostat; Organisation for Economic Co-operation and Development (OECD). What Are Equivalence Scales; Eurostat: Luxembourg, 2013; Available online: www.oecd.org/els/soc/OECD-Note-EquivalenceScales.pdf (accessed on 1 November 2018).

32. Edenhofer, O.; Pichs-Madruga, R.; Sokona, Y.; Minx, J.; Farahani, E.; Kadner, S.; Seyboth, K.; Adler, A.; Baum, I.; Brunner, S.; et al. Climate Change 2014: Mitigation of Climate Change Summary for Policymakers and Technical Summary; Intergovernmental Panel on Climate Change: Geneva, Switzerland, 2015; p. 66.

33. Anderson, K.; Peters, G. The trouble with negative emissions. Science 2016, 354, 182-183.

34. Shove, E. Beyond the ABC: Climate Change Policy and Theories of Social Change. Environ. Plan. A 2010, 42, 1273-1285. [CrossRef]

35. Chan, E.Y.Y.; Wang, S.S.; Ho, J.Y.; Huang, Z.; Liu, S.; Guo, C. Socio-demographic predictors of health and environmental co-benefit behaviours for climate change mitigation in urban China. PLoS ONE 2017, 12, e0188661. [CrossRef] [PubMed]

36. Beverland, M.B. Sustainable Eating: Mainstreaming Plant-Based Diets in Developed Economies. J. Macromarket. 2014, 34, 369-382. [CrossRef]

37. Barr, S.; Gilg, A.; Shaw, G. Citizens, consumers and sustainability: (Re)Framing environmental practice in an age of climate change. Glob. Environ. Chang. 2011, 21, 1224-1233. [CrossRef]

38. Kollmuss, A.; Agyeman, J. Mind the Gap: Why do people act environmentally and what are the barriers to pro-environmental behavior? Environ. Educ. Res. 2002, 8, 239-260. [CrossRef]

39. Chapman, L. Transport and climate change: A review. J. Transp. Geogr. 2007, 15, 354-367. [CrossRef]

40. Lea, E.J.; Crawford, D.; Worsley, A. Public views of the benefits and barriers to the consumption of a plant-based diet. Eur. J. Clin. Nutr. 2006, 60, 828. [CrossRef] [PubMed]

41. Joyce, A.; Dixon, S.; Comfort, J.; Hallett, J. Reducing the Environmental Impact of Dietary Choice: Perspectives from a Behavioural and Social Change Approach. J. Environ. Public Health 2012, 2012, 978672. [CrossRef] [PubMed]

42. Clarke, J.; Newman, J.; Smith, N.; Vidler, E.; Westmarland, L. Creating Citizen-Consumers: Changing Publics and Changing Public Services; Pine Forge Press: Newbury Park, CA, USA, 2007.

43. Barr, S.; Shaw, G.; Coles, T. Times for (Un)sustainability? Challenges and opportunities for developing behaviour change policy. A case-study of consumers at home and away. Glob. Environ. Chang. 2011, 21, 1234-1244. [CrossRef]

44. Barr, S.; Gilg, A.; Shaw, G. Helping People Make Better Choices': Exploring the behaviour change agenda for environmental sustainability. Appl. Geogr. 2011, 31, 712-720. [CrossRef] 
45. Taira, T.; Tabatabai, R.; Joshi, N. The Art of Choosing. Ann. Emerg. Med. 2016, 67, 684-685. [CrossRef]

46. Scheibehenne, B.; Greifeneder, R.; Todd, P.M. Can There Ever Be Too Many Options? A Meta-Analytic Review of Choice Overload. J. Consum. Res. 2010, 37, 409-425. [CrossRef]

47. Mayer, I.; Bekebrede, G.; Harteveld, C.; Warmelink, H.; Zhou, Q.; van Ruijven, T.; Lo, J.; Kortmann, R.; Wenzler, I. The research and evaluation of serious games: Toward a comprehensive methodology: The research and evaluation of serious games. Br. J. Educ. Technol. 2014, 45, 502-527. [CrossRef]

48. Minx, J.; Baiocchi, G.; Wiedmann, T.; Barrett, J.; Creutzig, F.; Feng, K.; Förster, M.; Pichler, P.; Weisz, H.; Hubacek, K. Carbon footprints of cities and other human settlements in the UK. Environ. Res. Lett. 2013, 8, 035039. [CrossRef]

49. Druckman, A.; Jackson, T. The carbon footprint of UK households 1990-2004: A socio-economically disaggregated, quasi-multi-regional input-output model. Ecol. Econ. 2009, 68, 2066-2077. [CrossRef]

(C) 2018 by the authors. Licensee MDPI, Basel, Switzerland. This article is an open access article distributed under the terms and conditions of the Creative Commons Attribution (CC BY) license (http:/ / creativecommons.org/licenses/by/4.0/). 